Ford, J. E., Perry, K. D. \& Briggs, C. A. E. (1958). J.gen. Microbiol. 18, 273-284

\title{
Nutrition of Lactic Acid Bacteria Isolated from the Rumen
}

\author{
By J. E. FORD \\ Nutrition Department \\ AND K. D. PERRY AND C. A. E. BRIGGS \\ Bacteriology Department \\ National Institute for Research in Dairying, University of Reading
}

SUMMARY: One hundred and seventeen strains of lactic acid bacteria from the rumen, representing four species of lactobacilli and four of streptococci, were examined for their requirements for vitamins. Of the lactobacilli only Lactobacillus plantarum ( 7 strains) was homogeneous in respect of its vitamin requirements. Within each of the other three species, strains differed in their requirements for individual vitamins, but on the whole the patterns of requirement were distinctive, and could be correlated with other specific characters. The vitamin requirements of three of the species (L. casei, L. plantarum and L. acidophilus) were broadly similar to those reported in a variety of non-rumen strains. Most of the rumen strains of $L$. fermenti required vitamin $\mathrm{B}_{6}$ and riboflavin, in addition to the requirement for nicotinic acid, thiamine and pantothenic acid variously reported as typical of the species. Streptococcus faecalis and $S$. liquefaciens had distinctive patterns of vitamin requirements as did the unclassified group. The remaining species, $S$. bovis, had no requirement for exogenous vitamins under the anaerobic test conditions used. Under conditions of aerobic culture, however, strains of this species were found to require one or more vitamins for growth.

In a study of the types of bacteria normally present in large numbers $\left(10^{9}\right.$ $10^{11} / \mathrm{ml}$.) in the rumens of cows and calves, some 350 strains of streptococci and 300 of lactobacilli were isolated; about a quarter of these were taken as representative, and identified (Perry, Wilson, Newland \& Briggs, 1955; Perry \& Briggs, 1957). The present study was carried out to determine the patterns of vitamin requirements in these rumen organisms and to establish to what extent these patterns are characteristic of the species as differentiated on the basis of bacteriological tests. A longer-term objective is to study symbiotic interrelationships between the more important rumen species, and the nutritional factors which may determine the equilibrium between the assorted populations present.

The nutrition of the lactic acid bacteria has been widely studied, and the vitamin requirements of representative strains have been worked out in detail (cf. Snell, 1948; Rogosa, Wiseman, Mitchell, Disraely \& Beaman, 1953). So far, however, very few strains from the rumen have been included in these studies. Jensen, Smith, Edmondson \& Merilan (1956) identified eight species of lactobacilli present in the bovine rumen at concentrations of $10^{6}$ or $10^{7} / \mathrm{ml}$. They concluded, on the basis of classical bacteriological tests, that none was indigenous to the rumen, and implied that their requirements for vitamins and 
amino acids did not require investigation, being already 'well known'. The implication is perhaps somewhat misleading, giving an impression that characteristic nutritional requirements can be precisely stated for each of the species. Against this, Russell, Bhandari \& Walker (1954), from a study of the vitamin requirements of lactic acid bacteria associated with brewery products, concluded that the vitamin requirements of different strains of any one species varied widely, though strains isolated from the same source tended to have the same requirements. In comparing the conclusions of different workers about the nutritional requirements of the lactobacilli one must bear in mind that these requirements can depend rather critically upon the conditions of test; they may be non-specific and sometimes more apparent than real (cf. Snell, 1948). For example, the absence of a requirement for vitamin $B_{12}$ in all 19 strains of Lactobacillus acidophilus examined in the present study contrasts with the finding by Rogosa et al. (1953) that a requirement for this vitamin was an important characteristic of the species, and may perhaps be related to the more strictly anaerobic conditions under which our tests have been done. There is, however, a broad area of agreement as to the requirements of certain species for particular vitamins, and it would seem that, despite all the factors making for variability, these nutritional requirements, under strictly defined conditions, are remarkably stable, and might well prove of value as an aid to classification.

The nutrition of several species of the genus Streptococcus has been studied in some detail, notably by Niven and his co-workers. Several strains of S.faecalis, $S$. liquefaciens, $S$. durans and $S$. zymogenes, all members of Lancefield's serological group D, were found (Niven \& Sherman, 1944) to have broadly similar vitamin requirements: all required biotin, nicotinic acid, pantothenic acid and vitamin $B_{6}$, and all except two required riboflavin. This pattern of vitamin requirement has been confirmed for $S$. faecalis by Nevin (1954). Niven \& Sherman (1944) concluded that, in their growth-factor requirements, the enterococci form a homogeneous group, but more recently they have recognized differences in the nutritional requirements of these species (Lake, Deibel \& Niven, 1957; and see below). Although belonging to the same serological group $\mathrm{D}, S$. bovis is apparently unique in the simplicity of its vitamin requirements (Niven, Washburn \& White, 1948). Most strains were reported to have an absolute requirement for biotin only, although thiamine, nicotinic acid and pantothenic acid were stimulatory and proved essential on prolonged serial subcultivation.

\section{METHODS}

The media and techniques used for the isolation and purification of the cultures have been described elsewhere (Perry et al. 1955; Perry \& Briggs, 1957). Most of the organisms were isolated from the rumen contents of cows or calves, though a few were obtained from sheep (K. D. Perry, unpublished). Seventy-six strains of lactobacilli, representing four species, and 37 strains of streptococci representing three species and one unclassified group, were grouped according to their patterns of vitamin requirements. 


\section{Cultural characteristics}

Lactobacilli. The results of the cultural tests used to differentiate these organisms into the four species are set out in Table 2. Serological tests confirmed this classification in representative strains of three of the species. This was not possible with Lactobacillus acidophilus, for which no antiserum was available.

Streptococci. The characteristics of the streptococci are shown in Table 3. All the isolates belonged to Lancefield's serological group D, within which they were divided according to their different cultural reactions into three distinct species and one uniform unclassified group.

\section{Vitamin requirements}

For the determination of vitamin requirements the following procedure was adopted. Freeze-dried cultures were seeded into a peptone + yeast extract + meat extract + sucrose + salt medium (Hirsch \& Grinsted, 1954), from which inoculations were made to tubes containing $10 \mathrm{ml}$. of 'complete' medium, of the composition shown in Table 1.

\section{Table 1. Composition of the 'complete' medium}

Solution of vitamin-free acidhydrolysed casein (see text)

Glucose

Sodium- $\beta$-glycerophosphate

Sodium acetate (hydrated)

$\mathrm{K}_{2} \mathrm{HPO}_{4}$

Potassium citrate (hydrated)

Ascorbic acid

Cysteine hydrochloride

Adenine

Guanine hydrochloride

Uracil

$\begin{aligned} 100 \mathrm{ml} . & \text { Xanthine } \\ 10 \mathrm{~g} . & \text { Solution of mineral salts } \\ 5 \mathrm{~g} . & \text { Pyeen } 80 \\ 4 \mathrm{~g} . & \text { Nicotinic acid } \\ \mathbf{2} \mathrm{g} . & \text { Calcium pantothenate } \\ \mathbf{0 . 6} \mathrm{g} . & \text { Thiamine hydrochloride } \\ 0.5 \mathrm{~g} . & \text { p-Aminobenzoic acid } \\ 50 \mathrm{mg} . & \text { Riboflavin } \\ 5 \mathrm{mg} . & \text { Folic acid } \\ 5 \mathrm{mg} . & \text { Biotin } \\ 5 \mathrm{mg} . & \text { Vitamin } \mathrm{B}_{12}\end{aligned}$

$5 \mathrm{mg}$.

$10 \mathrm{ml}$.

$1 \mathrm{ml}$.

$2 \mathrm{mg}$.

$1 \mathrm{mg}$.

$1 \mathrm{mg}$.

$1 \mathrm{mg}$.

$0.5 \mathrm{mg}$.

$0.5 \mathrm{mg}$.

$0.25 \mathrm{mg}$.

$10 \mu \mathrm{g}$.

$1 \mu \mathrm{g}$.

This mixture was made up in boiled distilled water to $1000 \mathrm{ml}$., the $\mathrm{pH}$ value having been adjusted to $6 \cdot 5-6 \cdot 7$.

The solution of vitamin-free acid-hydrolysed casein used in the 'complete' medium (Table 1) was made up as follows: $50 \mathrm{~g}$. 'vitamin-free' hydrolysed casein (Allen and Hanbury Ltd.) were dissolved in $700 \mathrm{ml}$. water. The $\mathrm{pH}$ value was adjusted to 3.8 with acetic acid, $10 \mathrm{~g}$. activated charcoal (Sutcliffe and Speakman Ltd., Grade 5) added, the mixture stirred for $1 \mathrm{hr}$. and filtered. The filtrate was adjusted to $\mathrm{pH} 6.5$ with $10 \mathrm{~N}-\mathrm{KOH}$, treated with a further $5 \mathrm{~g}$. charcoal, and filtered again. Finally, $1 \mathrm{~g}$. DL-tryptophan, $200 \mathrm{mg}$. each of $\mathrm{L}$-tyrosine and DL- $\beta$-phenylalanine and $100 \mathrm{mg}$. each of L-proline and L-histidine were dissolved into the filtrate, and the solution diluted to $1 \mathrm{l}$. with water.

The solution of mineral salts used in the 'complete' medium (Table 1) contained (g.): 20, $\mathrm{MgCl}_{2} .6 \mathrm{H}_{2} \mathrm{O} ; 5, \mathrm{CaCl}_{2}$ (anhyd.); 0.5, $\mathrm{FeCl}_{3} .6 \mathrm{H}_{2} \mathrm{O} ; 0.5$, $\mathrm{ZnSO}_{4} \cdot 7 \mathrm{H}_{2} \mathrm{O} ; 0 \cdot 5, \mathrm{MnSO}_{4} \cdot 4 \mathrm{H}_{2} \mathrm{O} ; 0 \cdot 25, \mathrm{CoCl}_{2} .6 \mathrm{H}_{2} \mathrm{O} ; 0 \cdot 25, \mathrm{CuSO}_{4} .5 \mathrm{H}_{2} \mathrm{O}$; $0 \cdot 25, \mathrm{VSO}_{4} ; 0.25, \mathrm{Na}_{2} \mathrm{MoO}_{4}$ dissolved in $1 \mathrm{l}$. distilled water with addition of $\mathrm{N}-\mathrm{H}_{2} \mathrm{SO}_{4}$ to clear. 
Table 2. Cultural characteristics of the lactobacilli tested*

\begin{tabular}{|c|c|c|c|c|}
\hline & L. fermenti & $\begin{array}{l}\text { L. acido- } \\
\text { philus }\end{array}$ & L. casei & L. plantarum \\
\hline No. of strains tested & 33 & 19 & 17 & 7 \\
\hline Production of gas from glucose & + & - & - & - \\
\hline Production of $\mathbf{N H}_{3}$ from arginine & + & - & - & - \\
\hline 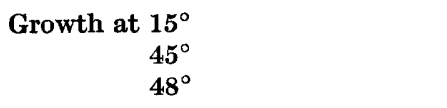 & $\begin{array}{l}+ \\
+ \\
-(20)\end{array}$ & $\begin{array}{l}- \\
+ \\
-\end{array}$ & $\begin{array}{l}+ \\
+ \\
-(12)\end{array}$ & $\begin{array}{l}+ \\
+ \\
-\end{array}$ \\
\hline $\begin{array}{r}\text { Growth with } \mathrm{NaCl} 4 \% \\
6 \%\end{array}$ & $\begin{array}{l}+(\mathbf{2 2}) \\
-\end{array}$ & $\begin{array}{l}+ \\
-\end{array}$ & $\begin{array}{l}+ \\
+\end{array}$ & $\begin{array}{l}+ \\
+(4)\end{array}$ \\
\hline $\begin{array}{r}\text { Growth with Teepol } 0.05 \% \\
0.1 \%\end{array}$ & NT & $\begin{array}{c}+ \\
\text { NT }\end{array}$ & $\begin{array}{l}\text { NT } \\
-\end{array}$ & $\begin{array}{c}\text { NT } \\
+\end{array}$ \\
\hline Growth with $\mathrm{KTeO}_{3} 0.01 \%$ & + & NT & NT & NT \\
\hline $\begin{array}{l}\text { Action in yeast extract glucose } \\
\text { litmus milk }\end{array}$ & sl. A & $\begin{array}{c}\text { AC } \\
\text { (3 days) }\end{array}$ & $\begin{array}{c}\text { AC } \\
\text { (2 days) }\end{array}$ & $\begin{array}{c}\mathrm{AC} \\
\text { (5 days) }\end{array}$ \\
\hline $\begin{array}{c}\text { Fermentation of: } \\
\text { Amygdalin }\end{array}$ & - & $+(15)$ & + & + \\
\hline Arabinose & + & - & $-(11)$ & + \\
\hline Cellobiose & - & + & + & + \\
\hline Dextrin & NT & + & NT & NT \\
\hline Glycerol & - & - & - & $+(4)$ \\
\hline Inositol & - & $-(13)$ & $+(10)$ & - \\
\hline Lactose & + & + & + & + \\
\hline Maltose & NT & + & NT & NT \\
\hline Mannitol & - & - & + & + \\
\hline Melezitose & - & - & + & + \\
\hline Melibiose & $+(\mathbf{1 8})$ & + & - & + \\
\hline Raffinose & + & + & - & + \\
\hline Rhamnose & - & - & $-(16)$ & - \\
\hline Salicin & $-(27)$ & + & + & + \\
\hline Sorbose & - & - & + & + \\
\hline Sucrose & + & + & + & + \\
\hline Trehalose & - & $+(12)$ & + & + \\
\hline Hydrolysis of aesculin & NT & + & NT & NT \\
\hline
\end{tabular}

The complete medium (Table 1) allowed abundant growth of all the isolates. The method of testing for vitamin requirements was to make, in parallel, three serial subcultures in: $(a)$ complete medium; $(b)$ complete medium modified by the omission of one of the eight vitamins-riboflavin, calcium pantothenate, nicotinic acid, pyridoxal hydrochloride, folic acid, biotin, thiamine hydrochloride or vitamin $\mathrm{B}_{12} ;(c)$ complete medium from which all eight vitamins were omitted simultaneously. Requirements for $p$-aminobenzoic acid were not investigated, and it was included in all the test media. The cultures were incubated at $39^{\circ}$ for $20 \mathrm{hr}$. in an atmosphere of $\mathrm{H}_{2} \mathbf{9 0} \%(\mathrm{v} / \mathrm{v})+\mathrm{CO}_{2} 10 \%(\mathrm{v} / \mathrm{v})$; a one-drop $(c .0 .5 \%)$ inoculum was transferred at each subculturing. Growth was assessed by visual observation of the tubes at $20 \mathrm{hr}$., and was scored as: - (no growth), \pm (slight growth),,+++ or +++ . 
Table 3. Cultural characteristics of the streptococci tested.

\begin{tabular}{|c|c|c|c|c|}
\hline & S. bovis & $\begin{array}{l}\text { S. lique- } \\
\text { faciens }\end{array}$ & S. faecalis & Unclassified \\
\hline Number of strains tested & 26 & $\mathbf{5}$ & 2 & 8 \\
\hline \multicolumn{5}{|c|}{ Serological (precipitin) reaction with antisera of: } \\
\hline Groups A-C, E-N & - & - & _- & - \\
\hline Group D & + & + & + & + \\
\hline Growth at $45^{\circ}$ & + & + & + & + \\
\hline with $\mathrm{NaCl}, 6 \cdot 5 \%$ & - & + & + & + \\
\hline at $\mathrm{pH} \mathrm{9.6}$ & - & + & + & + \\
\hline Survival at $60^{\circ}$ for $30 \mathrm{~min}$. & - & + & + & + \\
\hline Liquefaction of gelatin & - & + & - & - \\
\hline Hydrolysis of arginine & - & + & + & + \\
\hline Hydrolysis of starch & + & - & - & - \\
\hline Haemolysis in horse blood agar & $\alpha$ & sl. $\alpha$ & sl. $\alpha$ & $\alpha$ \\
\hline Action in litmus milk & sl. A & RC, pept. & ARC & ARC \\
\hline Growth with $0.04 \%(w / v) \mathrm{KTeO}_{3}$ : & NT & NT & + & - \\
\hline \multicolumn{5}{|l|}{ Fermentation of: } \\
\hline Arabinose & - & - & - & - \\
\hline Glycerol & - & + & + & + \\
\hline Inulin & + & - & - & - \\
\hline Mannitol & - & + & + & - \\
\hline Melezitose & NT & NT & + & - \\
\hline Melibiose & NT & NT & - & + \\
\hline Raffinose & + & - & + & + \\
\hline Sorbitol & - & + & + & - \\
\hline Sucrose & + & + & + & + \\
\hline Trehalose & - & + & + & + \\
\hline
\end{tabular}

sl. A : slight acidity; ARC: acidity, reduction and clotting; RC, pept.: reduction and clotting, followed by peptonization; NT: not tested.

We found that with most organisms the vitamin requirements were sharply defined and unequivocal. In the absence of a required vitamin there was no visible growth in the second or third subculture. An exception was the finding that growth of a few strains of Lactobacillus plantarum in the absence of vitamin $\mathbf{B}_{6}$ was severely limited, but continued at \pm through several transfers. Many of the tests were repeated, including all of those indicating the less common patterns of vitamin requirements. For example, the absence of a requirement for riboflavin in two strains of $L$. ferment $i$ was confirmed in parallel tests with strains which required riboflavin and in freshly prepared test medium.

Three of the cultures of lactobacilli appeared to have no requirement for vitamins, and were found on further investigation to be contaminated with Streptococcos bovis.

\section{RESULTS AND DISCUSSION}

\section{Lactobacilli}

The vitamin requirements found in the four species are shown in Table 4.

Lactobacillus casei. Several reports on the vitamin requirements of $\boldsymbol{L}$. casei differ only in detail. Rogosa et al. (1953) found that a requirement for riboflavin, pantothenic acid, nicotinic acid and folic acid, and poor growth without vitamin $\mathbf{B}_{\mathbf{6}}$, was characteristic of the species as represented by some hundreds 
of oral strains. This pattern is similar to that of most of our rumen strains, except that in all of these the need for vitamin $\mathbf{B}_{6}$ was absolute, and that for some of them folic acid was not required. Snell (1945) and Shankman et al. (1947) reported an additional requirement for biotin. The absence of this requirement in all the strains tested by Rogosa et al. (1953) and by ourselves is no doubt explained by the presence of oleate (as Tween 80 ) in our culture media, since it is known that for many lactic acid bacteria, oleate and biotin are physiologically equivalent, although for others (e.g. L. acidophilus) both substances are required (Kitay \& Snell, 1950). Our rumen isolates were broadly similar in their cultural reactions, but Rogosa et al. (1953), in a more searching comparison of the cultural reactions of their oral strains, recognized three varieties: $\boldsymbol{L}$. casei var. casei var.nov., which does not ferment rhamnose but ferments lactose; $L$. casei var. alactosus var.nov., which ferments neither rhamnose nor lactose; $L$. casei var. rhamnosus var.nov. which ferments both rhamnose and lactose. Within these three varieties there was considerable variation in fermentation reactions, though mostly in respect of substances which were fermented either weakly or not at all. It would seem then that these oral strains of $L$. casei were heterogeneous on the basis of their cultural reactions, albeit identical in their vitamin requirements. Conversely, in our rumen strains we have recognized two distinct patterns of vitamin requirement but no determining differences in cultural reactions, except possibly in the fermentation of rhamnose by one strain. Such differences as were evident(growth at $48^{\circ}$, fermentation of arabinose and inositol) could not be correlated with the different patterns of vitamin requirement. For comparison, we examined four stock strains of $L$. casei, originally isolated from milk or cheese. Two of these strains belonged to the serological group B of Sharpe \& Wheater (1957) and the other two strains to the same authors' serological group $C$. Three of the four strains had the same vitamin requirements as the rumen group $G$ (Table 4), and one the same as group H. A point of interest here is the overlapping of the subdivisions according to serological and nutritional features.

Lactobacillus fermenti. Of 148 oral strains of $L$. fermenti studied by Rogosa et al. (1953), $95 \%$ or more required thiamine, nicotinic acid and pantothenic acid. Shankman et al. (1947) reported that $L$. fermenti 36 needed only nicotinic acid and pantothenic acid, although Snell (1945) had found additional requirements for thiamine and biotin. All our rumen strains required nicotinic acid, pantothenic acid and thiamine; none required biotin, but 31 of the 33 required riboflavin and 26 required vitamin $B_{6}$. Our isolates were alike in most of their cultural characteristics, and we were content to assign them all to one group, but if greater significance were attached to small differences in fermentative abilities, further subdivision to 'varieties' would have been possible. From our experience we have preferred the more conservative approach, whereas Rogosa et al. (1953) were prepared to subdivide their strains into 12 groups on the basis of what we would have considered trivial differences in fermentation patterns. For comparison with our rumen strains we determined the vitamin requirements of four stock strains of $L$. fermenti originally isolated from cheese. Two of these strains, like the oral strains of Rogosa et al. (1953) required 


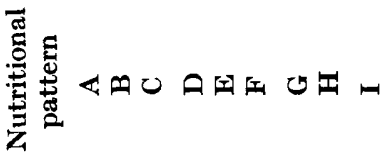

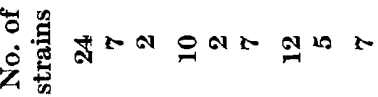

$\int \stackrel{\because}{\because}$ :

总 $111++1|1|$

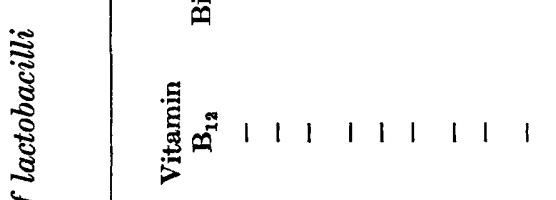

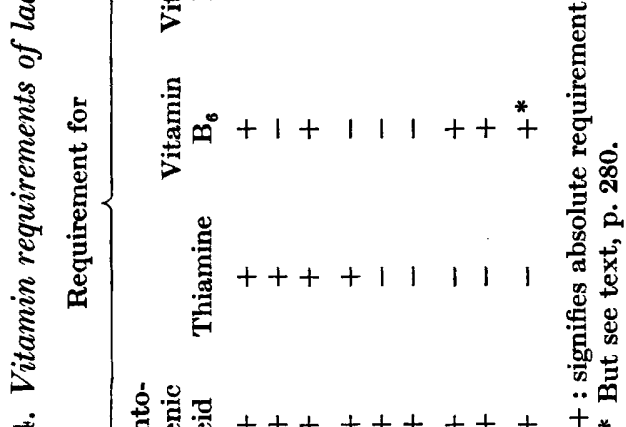

范

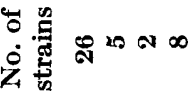

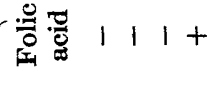

营 11111

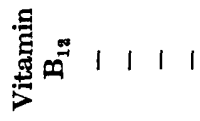

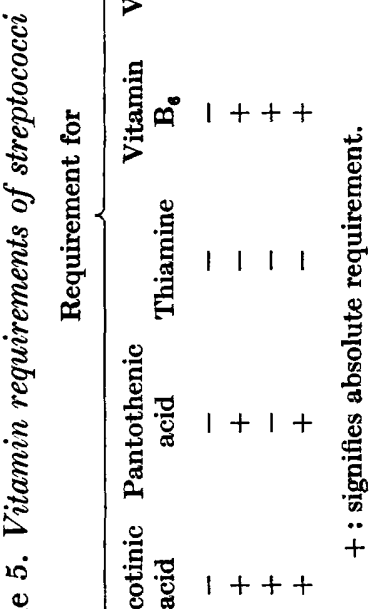

苞 $t+++++++$

$\stackrel{0}{\frac{0}{2 \pi}}$

递 $1++1$

运

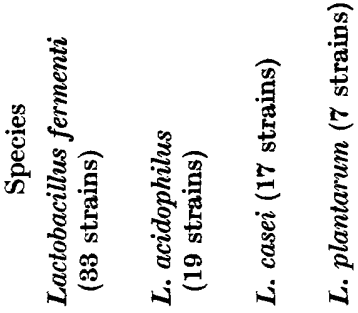

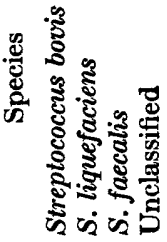


thiamine, nicotinic acid and pantothenic acid. One had a further requirement for riboflavin, as did the rumen group $B$ (see Table 4), whereas the fourth had an extra requirement for vitamin $\mathrm{B}_{6}$, like the rumen group C. As with L. casei, we were unable to correlate the different nutritional patterns within $L$. fermenti with any differences in cultural characteristics. A similar absence of detailed correlation between nutritional requirements and fermentation reactions is apparent in the findings of Rogosa et al. (1953).

Lactobacillus acidophilus. All of our strains of L. acidophilus required riboflavin, nicotinic acid, pantothenic acid and folic acid. In this they resemble the oral strains examined by Rogosa et al. (1953), which however also required vitamin $B_{12}$, vitamin $B_{6}$ being stimulatory. No need for these latter two vitamins was evident in our rumen isolates, two of which, however, had an additional requirement for biotin, and ten for biotin + thiamine. Kitay \& Snell (1950) found, in agreement with Rogosa et al. (1953), that vitamin $\mathrm{B}_{12}$ or deoxyribosides were essential for growth in 9 of 10 strains of $L$. acidophilus. It may well be that under different conditions of test a requirement for this vitamin would be manifest in our rumen strains. Our test medium was in fact virtually free from vitamin $B_{12}$; its composition was essentially the same as that of the medium we use routinely in the assay of vitamin $\mathrm{B}_{12}$ with $L$. leichmannii ATCC 4797 , which contains less than $1 \mu \mu \mathrm{g}$. vitamin $\mathrm{B}_{12} / \mathrm{ml}$. Kitay \& Snell (1950) also reported a requirement for pantetheine ('Lactobacillus bulgaricus factor') in 6 of 9 strains of L. acidophilus. None of our rumen isolates, nor any of the oral lactobacilli studied by Rogosa et al. (1953), showed a specific requirement for $L$. bulgaricus factor. The oral strains examined by Rogosa $e$ al . had uniform requirements for vitamins, and were similar in their cultural reactions. Our rumen strains, on the other hand, were less consistent in their fermentation reactions, and fell into three distinct subgroups according to their different patterns of vitamin requirements.

Lactobacillus plantarum. For our rumen strains nicotinic acid and pantothenic acid were required, and without added vitamin $B_{6}$ growth was severely limited. Rogosa et al. (1953) recognized two distinct nutritional types in their oral isolates. One required nicotinic acid and pantothenic acid; the other required nicotinic acid and riboflavin, and grew very poorly in the absence of pantothenic acid. The strains which required riboflavin were further subdivided into two groups on the basis of marked differences in their fermentation reactions. Those which required nicotinic acid and pantothenic acid, however, had uniform and distinctive fermentation reactions, and Rogosa et al. (1953) gave important reasons for concluding that these latter strains are identical with the L. arabinosus of Fred, Peterson \& Anderson (1921). This they claimed to be a species quite distinct from L. plantarum. Whether or not this is so, the isolates resemble our rumen strains very closely, both in cultural characteristics and vitamin requirements. On the question of the status of $L$. arabinosus as a distinct species we prefer to reserve our opinion as all our rumen strains give a positive reaction with the group D $(L$. plantarum) antiserum of Sharpe \& Wheater (1957). 


\section{Streptococci}

The vitamin requirements found for the streptococci are shown in Table 5.

Streptococcus bovis. None of the 26 strains tested required exogenous vitamins, though 5 grew poorly in the absence of thiamine. These findings contrast with those of Niven et al. (1948), most of whose strains required only biotin, but were said (somewhat paradoxically) to require also thiamine, pantothenic acid and nicotinic acid on prolonged subcultivation. To allow a closer comparison of our findings with those of Niven et al. (1948), we repeated several of the tests, incubating the cultures aerobically. Growth under these conditions was less vigorous, and several patterns of vitamin requirement became apparent. Thus, nine of our strains failed to grow without nicotinic acid, and three without nicotinic acid and biotin. One required nicotinic acid, biotin and thiamine; four required biotin and thiamine and one required biotin. These aerobic requirements were not entirely constant and are presumably not absolute: they are evidently imposed more by the conditions of culture than by an inherent inability to synthesise these essential metabolites. Our rumen strains of $S$. bovis were uniform in their cultural reactions, except that two strains fermented trehalose, one arabinose, and one strain fermented both sugars. Their cultural characteristics are very similar to those of the strains described by Niven et al. (1948), and the organisms may well be identical, despite the inconclusive evidence of the nutritional tests.

Streptococcus liquefaciens. The five strains of $S$. liquefaciens required riboflavin, nicotinic acid, pantothenic acid and vitamin $B_{6}$, whether they were grown aerobically or anaerobically; they were identical also in their cultural reactions. Niven \& Sherman (1944), who used a medium free from oleate, found that biotin also was required. These vitamin requirements recall those of $L$. casei, and are indeed the same as those of our $L$. casei subgroup $\mathbf{H}$ (Table 4).

Streptococcus faecalis. Two of the streptococci were identified as $S$. faecalis and required vitamin $B_{6}$, nicotinic acid and riboflavin. The absence of a requirement for folic acid accords with the findings of Lake et al. (1957); these workers used this criterion to differentiate $S$. faecalis and its varieties from $S$. faecium and $S$. durans. By implication, strains of $S$. faecalis reported as requiring folic acid (Niven \& Sherman, 1944) should be re-assigned to $S$. faecium; but so much of the classical work on folic acid has been carried out with deficient strains of ' $S$. faecalis' that any such belated revision of the nomenclature would seem likely to create misunderstanding.

Unclassified strains. The eight strains examined required nicotinic acid, pantothenic acid, vitamin $\mathbf{B}_{6}$ and folic acid, and were identical in their cultural reactions. Absence of growth in presence of $0.04 \%(\mathrm{w} / \mathrm{v}) \mathrm{KTeO}_{3}$ and requirement for folic acid suggested that they did not belong to the Streptococcus faecalis group; the remaining group D species, S. bovis, S. durans and $S$. faecium were excluded respectively, on the results of tests for heat survival and growth at $\mathrm{pH} 9 \cdot 6$ or in $6.5 \% \mathrm{NaCl}$; haemolysis in horse blood agar and fermentation of sucrose and raffinose; fermentation of arabinose and raffinose. These eight 
strains resemble certain unclassified isolates from the gut of the pig (Fewins, Newland \& Briggs, 1957).

\section{CONCLUSIONS}

Of the four species of rumen lactobacilli examined only Lactobacillus plantarum (represented by 7 strains) was homogeneous in respect of its vitamin requirements. Within each of the other three species, strains differed in respect of their requirements for individual vitamins, but on the whole the patterns of requirement appeared to be characteristic, in that they were correlated with other specific characters. On the wider question of the extent to which these nutritional patterns can be held to differentiate the species and subspecies it will clearly be necessary to investigate a fuller range of representative strains.

The vitamin requirements of three of the species of rumen lactobacilli, namely Lactobacillus casei, L. plantarum and L. acidophilus, were broadly similar to those reported for a number of non-rumen strains, as also were most of the cultural characteristics, and there seems little reason to suppose that the rumen strains are in any way different from strains previously isolated from other sources. Rogosa et al. (1953) came to the same conclusion with regard to their oral strains. There is in the findings of Russell et al. (1954) the suggestion that lactobacilli isolated from sour beers and brewers' yeasts are different from their counterparts in milk in that none of 32 isolates, representing 8 species, required folic acid or biotin. This may be so but it seems to us possible that the method of analysis adopted by Russell $e t$ al. would not have brought to light any requirements for these more 'potent' vitamins. We found in general that requirements for thiamine, riboflavin, nicotinic acid and pantothenic acid were manifest at the first transfer into deficient media, whereas requirements for vitamin $\mathbf{B}_{6}$, folic acid and biotin were not apparent until the second or even the third transfer. To assess the vitamins as 'essential', 'stimulatory' or 'non-essential' on the evidence of a single transfer into the deficient media, as was done by Russell et al. (1954) and by several other workers (e.g. Anderson \& Elliker, 1953) seems to us therefore to be less than adequate, and perhaps misleading. One suspects that vitamins in the 'stimulatory' category would be judged 'essential' on further investigation, and that certain 'non-essential' vitamins might in fact be required.

Most of our rumen strains of Lactobacillus fermenti required riboflavin and vitamin $B_{6}$ in addition to the requirement for nicotinic acid, thiamine and pantothenic acid reported as typical of the species by Rogosa et al. (1953). Under our conditions of test requirements for riboflavin or vitamin $B_{6}$ were also found in strains of $L$. fermenti from cheese. Thus there seems no reason to suppose that the rumen strains are unique in their vitamin requirements.

In general, our assessment of the vitamin requirements of Streptococcus faecalis and $S$. liquefaciens confirms the findings of Niven and his co-workers. In $S$. bovis, however, we found no absolute requirement for vitamins under our conditions of test. The unclassified strains were homogeneous in respect of their vitamin requirements and cultural characters, which together differentiated them from named streptococcal species. From a comparison of cultural 
characteristics, it seems likely that these strains may be the same as the unclassified isolates of Fewins et al. (1957) from the gut of the pig.

Our experience in carrying out this limited survey of the rumen lactic acid bacteria has impressed us with the potential value of information on comparative nutrition in studies of bacterial taxonomy. We have at this Institute a collection of fully classified cultures, representative of all the accepted species in the genus Lactobacillus, and we plan to extend the investigation reported in this paper to include several strains of each of these species.

We would like to thank Mrs O. M. Bullock for her considerable help; we would also like to thank Dr S. K. Kon, Dr A. T. R. Mattick and Dr M. E. Sharpe for their interest and advice.

\section{REFERENCES}

Anderson, A. W. \& Elliker, P. R. (1953). The nutritional requirements of lactic streptococci isolated from starter cultures. I. Growth in a synthetic medium. J. Dairy Sci. 36, 161.

Fewins, B. G., Newland, L. G. M. \& Briggs, C. A. E. (1957). The normal intestinal flora of the pig. III. Qualitative studies of lactobacilli and streptococci. J. appl. Bact. 20, 234.

Fred, E. B., Peterson, W. H. \& Anderson, J. A. (1921). The characteristics of certain pentose-destroying bacteria, especially as concerns their action on arabinose and xylose. J. biol. Chem. 48, 385 .

Hirsch, A. \& Grinsted, E. (1954). Media for the growth and enumeration of anaerobic spore formers from cheese with observations on the effect of nisin. J. Dairy Res. 21, 101.

Jensen, R. G., Smith, K. L., Edmondson, J. W. \& Merilan, C. P. (1956). The characteristics of some rumen lactobacilli. J. Bact. 72, 253.

KitAY, E. \& SNELL, E. E. (1950). Some additional nutritional requirements of certain lactic acid bacteria. J. Bact. 60, 49.

Lake, D. E., Deibel, R. H. \& Niven, C. F. (1957). The identity of Streptococcus faecium. Paper presented at the meeting of the Society of American Bacteriologists, Detroit, Michigan. (29 April 1957.)

Nevis, T. A. (1954). The vitamin requirements of certain alpha-hemolytic streptococci isolated from the human mouth. $J$. Bact. 67, 217.

Niven, C. F. \& Sherman, J. M. (1944). Nutrition of the enterococci. J. Bact. 47, 335.

Niven, C. F., Washburn, M. R. \& White, J. C. (1948). Nutrition of Streptococcus bovis. J. Bact. 55, 601.

Perry, K. D. \& Briggs, C. A. E. (1957). The normal flora of the bovine rumen. IV. Qualitative studies of lactobacilli from cows and calves. J. appl. Bact. 20, 119.

Perry, K. D., Wilson, M. K., Newland, L. G. M. \& Briggs, C. A. E. (1955). The normal flora of the bovine rumen. III. Quantitative and qualitative studies of rumen streptococci. J. appl. Bact. 18, 436.

Rogosa, M., Wiseman, R. F., Mrtchell, J. A., Disraely, M. N. \& Beaman, A. J. (1953). Species differentiation of oral lactobacilli from man including descriptions of Lactobacillus salivarius nov.spec. and Lactobacillus cellobiosus nov.spec. J. Bact. 65, 681.

Russell, C., Bhandari, R. R. \& Walker, T. K. (1954). Vitamin requirements of thirty-four lactic acid bacteria associated with brewery products. J. gen. Microbiol. 10, 371. 
Shankman, S., Camien, M. N., Block, H., Merrifield, R. B. \& DunN, M. S. (1947). Vitamin requirements of 23 lactic acid bacteria. J. biol. Chem. 168, 23.

SharPe, M. E. \& Wheater, D. M. (1957). Lactobacillus helveticus. J. gen. Microbiol. 16, 676 .

SNELL, E. E. (1945). The nutritional requirements of the lactic acid bacteria and their application to biochemical research. J. Bact. 50, 373.

SNELL, E. E. (1948). Nutritional requirements of the lactic acid bacteria. Wallerstein Lab. Commun. 11, 81. 